\title{
Ultrasonic assisted synthesis, acoustical property and antibacterial activity of some Schiff bases
}

\author{
R. Premalatha, N. Santhi ${ }^{*}$ \\ Department of Chemistry, Government Arts College, C-Mutlur - 608 102, Chidambaram, India \\ *Tel.: +914144238292 \\ *E-mail address: nsaaanthi@gmail.com
}

\begin{abstract}
An efficient, simple clean synthesis of Schiff bases of some 4-nitroaniline/ 2,4-dinitroaniline/ 3,4-dichloroaniline / 4-methoxy-3-nitro aniline with 3-bromo-4-fluorobenzaldehyde were done by an ultrasound irradiation method. The major advantages of ultra-sonication are short reaction time, operational simplicity, high yield, easy workup and environment friendly procedure. The isolated compounds obtained by ultrasound irradiation method were characterized by UV, IR and NMR spectral data. These acoustical parameters were determined. Furthermore their antibacterial activities are screened against certain strains of bacteria and showed significant anti-microbial activity.
\end{abstract}

Keywords: Substituted anilines; 3-bromo-4-fluorobenzaldehyde; Schiff bases; ultrasonication; acoustical parameters and antimicrobial activity

\section{INTRODUCTION}

Compounds containing azomethine group $(-\mathrm{C}=\mathrm{N}-)$ usually known as Schiff bases which have been synthesized by the condensation of primary amines with active carbonyls compounds such as aldehydes or ketones. Schiff bases form a significant class of compounds in medicinal and pharmaceutical chemistry with several biological applications which includes antibacterial $^{1-3}$, antifungal ${ }^{4}$ and antitumor activities ${ }^{5}$. Conventionally, Schiff's bases can be prepared by refluxing the primary amines and aldehyde/ketone in an organic solvents and presence of traces of acid or base. Sonchemistry is one of the green chemistry research area in which molecules undergo a reaction due to the application of powerful ultrasonic radiation. The ultrasound irradiation is a powerful technique ${ }^{6}$ for establishing unique chemical and physical conditions, such as a local increase in temperature of several thousands of Kelvins and pressure by several bars by which reaction proceeds. This method has several advantages such as higher atom economy, energy efficiency, environmental friendly, waste and hazards minimization etc. The above findings by various group of scientist stimulated us to synthesize new Schiff bases using classical as well as green technique.

Further, it provides a wealth of information about molecular interactions, nature and strength of interactions. In recent years, much effort has been made to study ultrasonic properties of liquid mixtures ${ }^{7-10}$. However, scanty work has been done for solutions of organic compounds. In the last few years, our investigation groups have carried out some studies on acoustical properties of organic compounds in various solvents ${ }^{11-16}$. In continuation of these 
investigations, the present paper reports acoustical properties of Schiff bases in ethanol at $303.15 \mathrm{~K}$ and their antibacterial activities.

\section{MATERIALS AND METHODS}

All the chemicals 2-nitroaniline, 2,4-dinitroaniline, 3,4-dichloroaniline, 4-methoxy-3nitro aniline and 3-bromo-4-fluorobenzaldehyde were procured from Sigma-Aldrich, India, Banglore. All the solvents were of analytical grade and were distilled before use. Melting points of the synthesized compounds were determined in open capillaries on melting point apparatus and are uncorrected. Infrared spectra $\left(\mathrm{KBr}, 4000-400 \mathrm{~cm}^{-1}\right)$ have been recorded on SHIMADZU Fourier transform spectrophotometer. The NMR spectra were recorded in Bruker AMX 500 NMR spectrometer operating at $5400 \mathrm{MHz}$ has been utilized for recording ${ }^{1} \mathrm{H}$ NMR spectra and $100 \mathrm{MHz}$ for ${ }^{13} \mathrm{C}$ spectra in $\mathrm{CDCl}_{3}$ solvent using TMS as internal standard. Ultra-sonication was done at 3.5L 100 at Govt. Arts College, Chidambaram, Tamilnadu.

An appropriate equimolar quantity of the following substituted anilines $(0.01 \mathrm{~mol})$ with 3-bromo-4-fluorobenzaldehyde $(0.01 \mathrm{~mol})$ and absolute ethanol $(10 \mathrm{ml})$ were taken in $150 \mathrm{ml}$ conical flak. To this mixture, glacial acetic acid ( 1 drop) was added. The mixture was partially submerged in the sonic bath ${ }^{17}$ at room temperature at $25-30{ }^{\circ} \mathrm{C}$ as shown in Fig. 1. The completion of the reaction was monitored by TLC and the mixture was cooled at room temperature. The resulting precipitate was filtered and washed with cold water. The product appeared as pale yellow solids. Then this was recrystallized using ethanol to obtain pale yellow glittering solid.

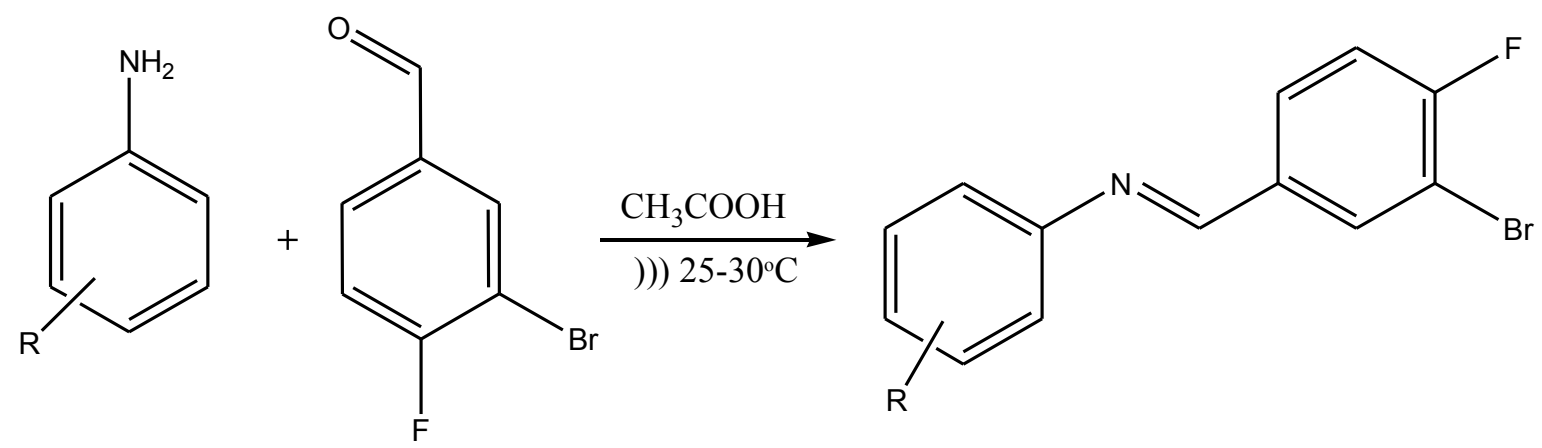

Where, $\mathrm{R}=4$-Nitro phenyl; 2,4-dinitro phenyl; 3,4-dichloro phenyl and 4-methoxy-3-nitro phenyl

Fig. 1. Spectroscopic data of synthesized compounds.

(i) (E)-N-(3-bromo-4-fluorobenzylidene)-4-nitrobenzenamine (4N):

UV $\left(\lambda_{\max }\right): 313.0 \mathrm{~nm}$; IR $\left(\mathrm{vcm}^{-1}\right): 1622.13(\mathrm{C}=\mathrm{N}), 3064.89\left(\mathrm{CH}_{s t r}\right), 1564.27\left(\mathrm{Phenyl}_{s t r}\right)$, $1465.90\left(\mathrm{CH}_{b e n}\right) ;{ }^{1} \mathrm{H}$ NMR $\left(\delta_{p p m}\right): 8.776(s, 1 \mathrm{H})(\mathrm{CH}=\mathrm{N}) ;{ }^{13} \mathrm{C} \operatorname{NMR}\left(\delta_{p p m}\right): 160.79(\mathrm{C}=\mathrm{N})$.

(ii) (E)-N-(3-bromo-4-fluorobenzylidene)-2,4-dinitrobenzenamine (DN):

UV $\left(\lambda_{\max }\right): 310.4 \mathrm{~nm}$; IR $\left(\mathrm{vcm}^{-1}\right): 1620.21(\mathrm{C}=\mathrm{N}), 3062.96\left(\mathrm{CH}_{s t r}\right), 1568.13\left(\mathrm{Phenyl}_{\text {str. }}\right)$, $1465.90\left(\mathrm{CH}_{\text {ben }}\right) ;{ }^{1} \mathrm{H} \mathrm{NMR}\left(\delta_{p p m}\right): 8.386(s, 1 \mathrm{H})(\mathrm{CH}=\mathrm{N}) ;{ }^{13} \mathrm{C} \operatorname{NMR}\left(\delta_{p p m}\right): 161.906(\mathrm{C}=\mathrm{N})$. 
(iii) (E)-N-(3-bromo-4-fluorobenzylidene)-3,4-dichlorobenzenamine (DC):

$\mathrm{UV}\left(\lambda_{\max }\right): 328.2 \mathrm{~nm}$; IR $\left(\mathrm{vcm}^{-1}\right): 1618.28(\mathrm{C}=\mathrm{N}), 3076.46\left(\mathrm{CH}_{s t r}\right), 1570.06\left(\right.$ Phenyl $\left._{s t r}\right)$, $1514.12\left(\mathrm{CH}_{\text {ben }}\right) ;{ }^{1} \mathrm{H} \mathrm{NMR}\left(\delta_{p p m}\right): 8.610(s, 1 \mathrm{H})(\mathrm{CH}=\mathrm{N}) ;{ }^{13} \mathrm{C} \operatorname{NMR}\left(\delta_{p p m}\right): 162.550(\mathrm{C}=\mathrm{N})$.

(iv) (E)-N-(3-bromo-4-fluorobenzylidene)-4-methoxy-3-nitrobenzenamine (4MN):

UV $\left(\lambda_{\text {max }}\right): 345.8 \mathrm{~nm}$; IR $\left(\mathrm{vcm}^{-1}\right)$ : $1624.06(\mathrm{C}=\mathrm{N}), 3078.39\left(\mathrm{CH}_{\text {str. }}\right), 1568.13$ (Phenyl $\left.\mathrm{P}_{\text {str }}\right)$, $1465.90\left(\mathrm{CH}_{\text {ben }}\right) ;{ }^{1} \mathrm{H}$ NMR $\left(\delta_{p p m}\right): 8.668(s, 1 \mathrm{H})(\mathrm{CH}=\mathrm{N}), 3.329(s, 3 \mathrm{H}) ;{ }^{13} \mathrm{C} \operatorname{NMR}\left(\delta_{p p m}\right)$ : $163.455(\mathrm{C}=\mathrm{N}), 55.570\left(-\mathrm{OCH}_{3}\right)$.

\section{RESULTS AND DISCUSSION}

\section{1. Molecular interactions}

The density $(\rho)$, viscosity $(\eta)$ and sound velocity $(U)$ of pure solvents and different Schiff bases solutions in ethanol are reported in Table 1 at $303.15 \mathrm{~K}$. The calculated parameters of all compounds were also given in Table 2 .

Table 1. Variation of Ultrasonic velocity, Density and Viscosity parameters with various concentrations of Schiff bases at $303.15 \mathrm{~K}$ in ethanol.

\begin{tabular}{|c|c|c|c|c|}
\hline \multirow{3}{*}{ Compounds } & $\begin{array}{c}\text { Concentration } \\
(\mathrm{M})\end{array}$ & $\begin{array}{c}\text { Ultrasonic velocity } \\
(\mathrm{U})(\mathrm{m} / \mathrm{s})\end{array}$ & $\begin{array}{c}\text { Density } \\
\left(\mathrm{g} / \mathrm{m}^{3}\right)\end{array}$ & Viscosity $(\eta)$ (mPa.s) \\
\hline \multirow{4}{*}{$\mathbf{4 N}$} & 0.01 & 1014.8 & 0.8005 & 0.5483 \\
\cline { 2 - 5 } & 0.03 & 1023.6 & 0.8024 & 0.5644 \\
\cline { 2 - 5 } & 0.05 & 1027.4 & 0.8102 & 0.5713 \\
\hline \multirow{4}{*}{ DN } & 0.07 & 1031.7 & 0.8181 & 0.5801 \\
\cline { 2 - 5 } & 0.01 & 1017.0 & 0.8151 & 0.5419 \\
\cline { 2 - 5 } & 0.03 & 1024.4 & 0.8246 & 0.5504 \\
\hline \multirow{4}{*}{ DC } & 0.05 & 1091.7 & 0.8281 & 0.559 \\
\cline { 2 - 5 } & 0.07 & 1108.2 & 0.8304 & 0.5708 \\
\cline { 2 - 5 } & 0.01 & 1077.6 & 0.8027 & 0.6030 \\
\cline { 2 - 5 } & 0.03 & 1117.7 & 0.8031 & 0.6224 \\
\hline \multirow{4}{*}{$4 \mathbf{M N}$} & 0.05 & 1130.4 & 0.8043 & 0.6341 \\
\cline { 2 - 5 } & 0.07 & 1151.6 & 0.8061 & 0.6472 \\
\cline { 2 - 5 } & 0.01 & 1304.0 & 0.7874 & 0.7324 \\
\cline { 2 - 5 } & 0.03 & 1368.3 & 0.7912 & 0.7384 \\
\hline & 0.05 & 1412.6 & 0.8064 & 0.7414 \\
\hline
\end{tabular}

From Table 1, it is evident that the ultrasonic velocities, densities and viscosities of all the four Schiff bases were increases with respect to concentration. The increasing tendency of 
such parameters indicates the close association between solute and solvent molecules. These variations are shown in Fig. 2, Fig. 3 and Fig. 4.

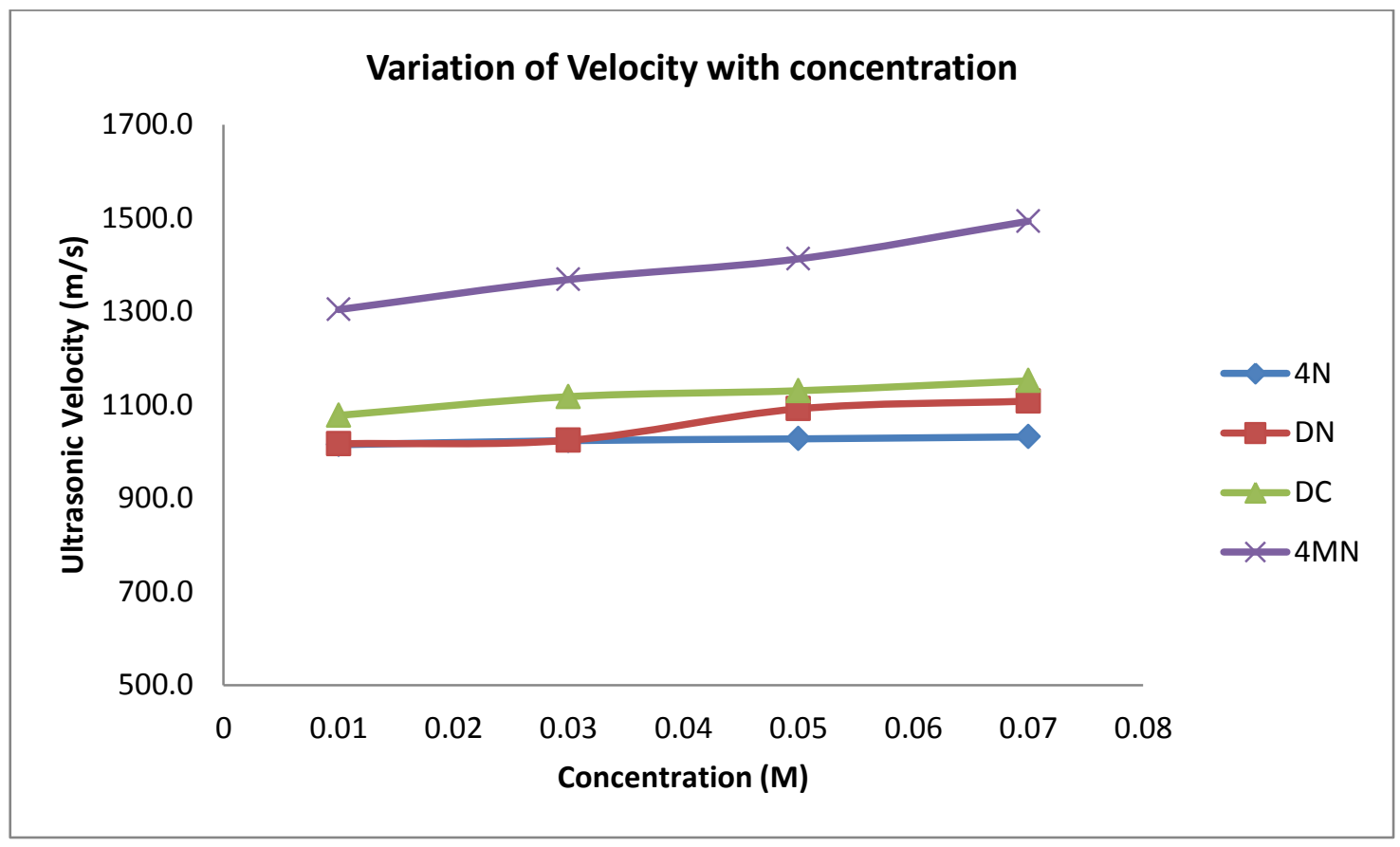

Fig. 2. Variation of Ultrasonic velocity (U) with respect to concentration (M).

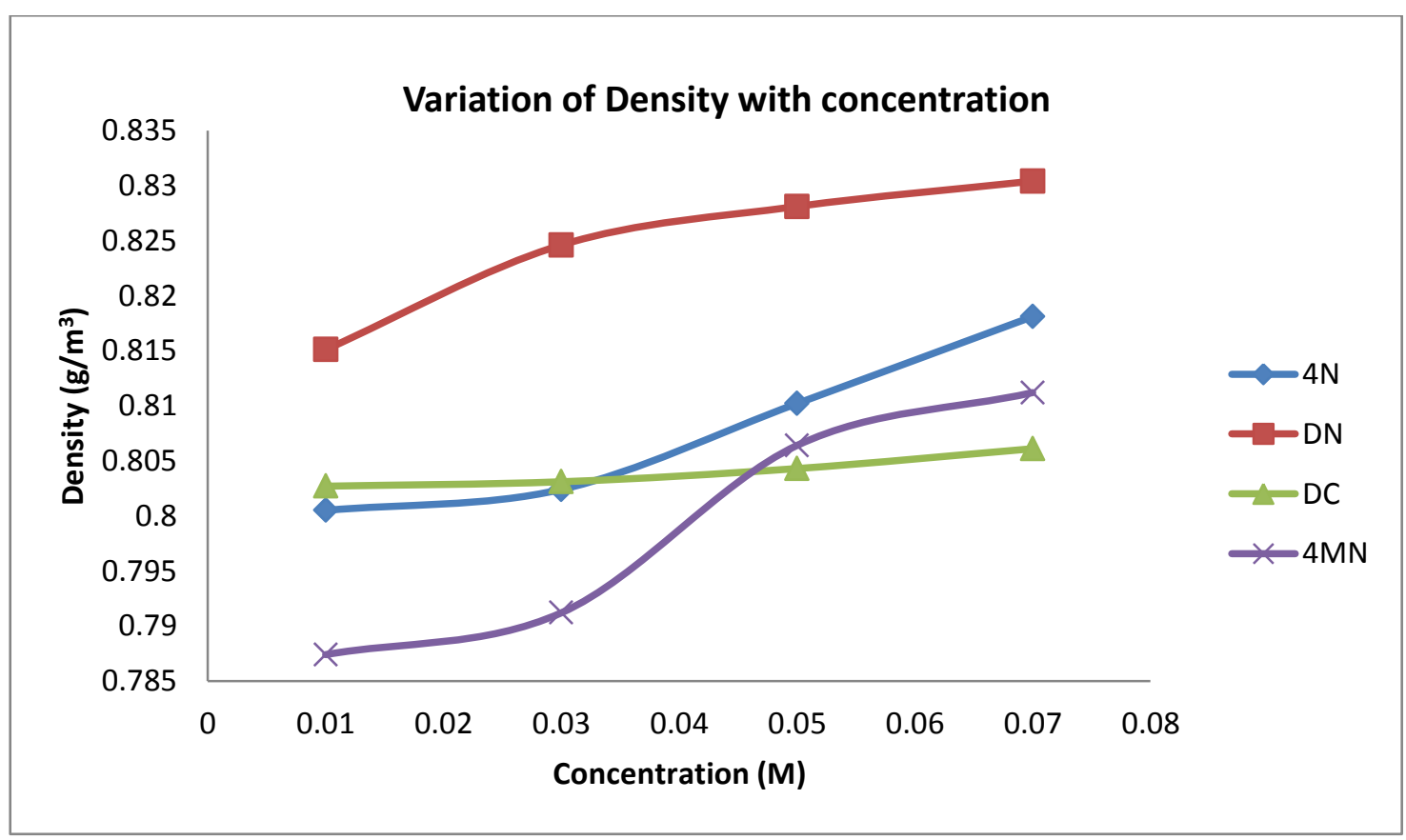

Fig. 3. Variation of Density ( $\rho$ ) with respect to concentration (M). 


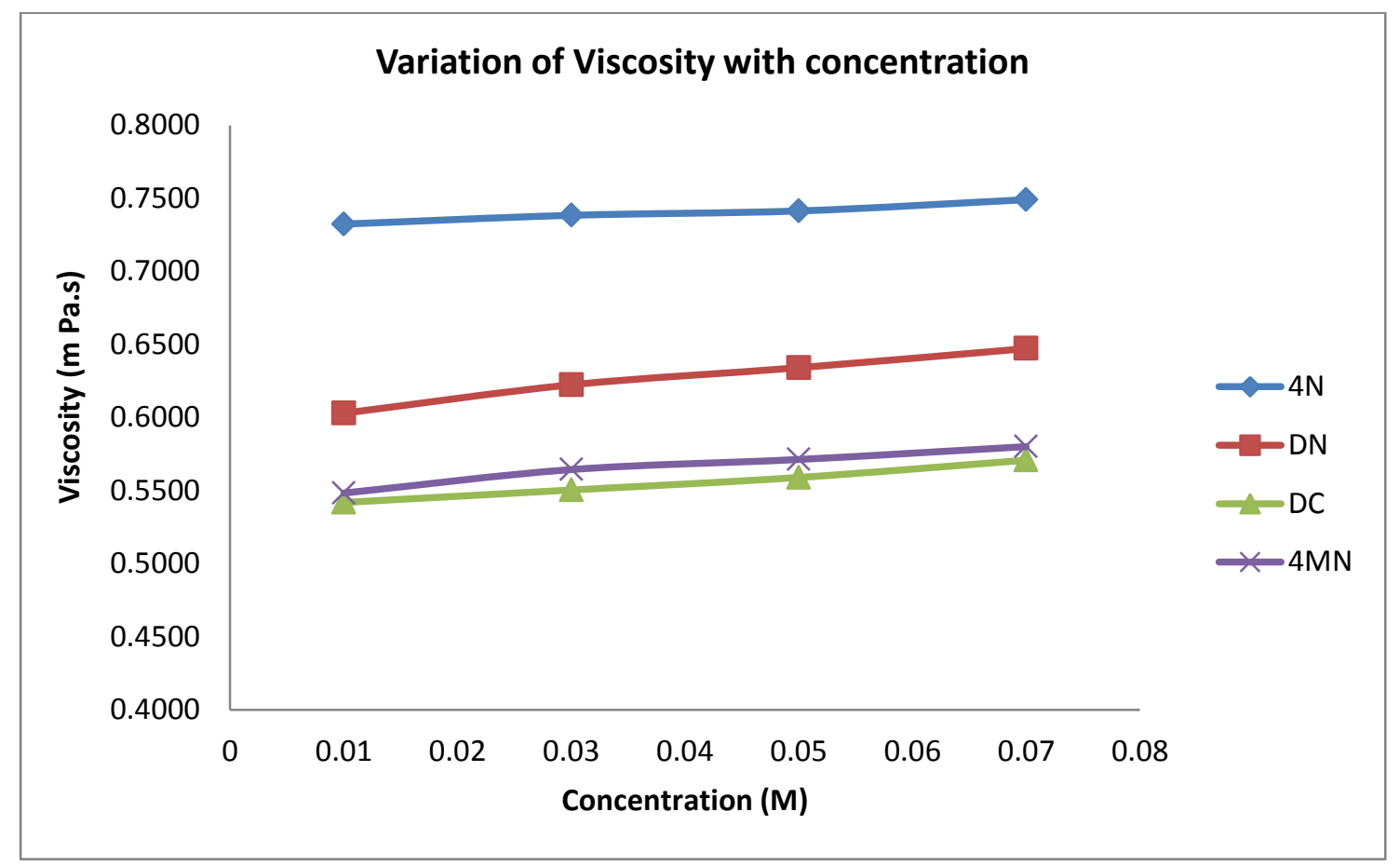

Fig. 4. Variation of Viscosity ( $\eta$ ) with respect to concentration (M).

This increase in ultrasonic velocity suggests powerful solute-solvent interactions. As density increase number of particles in given region is increased, this leads to quick transfer of sound velocity and hence velocity increases with increase in concentration, this result is according to Kharkale t. al ${ }^{18}$.

The density increases with increasing concentration. The increase of concentration results in increase in number of particles in given region which leads to shrinkage in volume of solution and hence density increases with increase in concentration ${ }^{19}$. Also viscosity increases linearly with concentration and it indicates the existence of strong interaction between solute and solvent.

Table 2. Variation of some acoustical parameters with concentration of Schiff bases at $303.15 \mathrm{~K}$ in ethanol.

\begin{tabular}{|c|c|c|c|c|c|c|}
\hline Compounds & $\begin{array}{l}\text { Concentration } \\
\text { (M) }\end{array}$ & $\begin{array}{c}\text { Adiabatic } \\
\text { Compressibility } \\
(\beta \mathrm{ad}) \\
\left(10^{-10} \mathrm{~Pa}^{-1}\right)\end{array}$ & $\begin{array}{l}\text { Intermolecular } \\
\text { Free length } \\
\left(\mathrm{L}_{\mathrm{f}}\right) \mathrm{A}^{0}\end{array}$ & $\begin{array}{c}\text { Specific } \\
\text { acoustic } \\
\text { impedance } \\
(\mathrm{Z}) \\
\mathrm{kg} / \mathrm{m} 2 \mathrm{~s}\end{array}$ & $\begin{array}{l}\text { Free } \\
\text { volume } \\
\left(\mathrm{V}_{\mathrm{f}}\right)\end{array}$ & $\begin{array}{c}\text { Internal } \\
\text { Pressure } \\
\quad\left(\pi_{\mathrm{i}}\right)\end{array}$ \\
\hline \multirow{2}{*}{$4 N$} & 0.01 & 1.2130 & 0.1032 & 812.347 & 0.0968 & 7.0892 \\
\hline & 0.03 & 1.1895 & 0.1022 & 821.336 & 0.1104 & 6.3267 \\
\hline
\end{tabular}




\begin{tabular}{|c|c|c|c|c|c|c|}
\hline & 0.05 & 1.1693 & 0.1013 & 832.399 & 0.1261 & 5.7095 \\
\hline & 0.07 & 1.1512 & 0.1004 & 844.033 & 0.1416 & 5.2115 \\
\hline \multirow{4}{*}{ DN } & 0.01 & 1.4070 & 0.1021 & 828.956 & 0.1002 & 7.0495 \\
\hline & 0.03 & 1.1556 & 0.1007 & 844.72 & 0.119 & 6.1804 \\
\hline & 0.05 & 1.1507 & 0.0943 & 904.036 & 0.1508 & 5.325 \\
\hline & 0.07 & 0.9806 & 0.0928 & 920.249 & 0.1733 & 4.7688 \\
\hline \multirow{4}{*}{ DC } & 0.01 & 1.0728 & 0.0971 & 864.989 & 0.0925 & 7.1865 \\
\hline & 0.03 & 0.9967 & 0.0936 & 897.624 & 0.1109 & 6.2647 \\
\hline & 0.05 & 0.9730 & 0.0924 & 909.18 & 0.1282 & 5.576 \\
\hline & 0.07 & 0.9354 & 0.0973 & 927.153 & 0.1472 & 5.0046 \\
\hline \multirow{4}{*}{$4 \mathrm{MN}$} & 0.01 & 0.7469 & 0.081 & 1026.77 & 0.0922 & 7.0979 \\
\hline & 0.03 & 0.6751 & 0.077 & 1082.599 & 0.1168 & 6.0829 \\
\hline & 0.05 & 0.6215 & 0.0739 & 1139.121 & 0.1427 & 5.3722 \\
\hline & 0.07 & 0.5530 & 0.0697 & 1211.203 & 0.1762 & 4.7179 \\
\hline
\end{tabular}

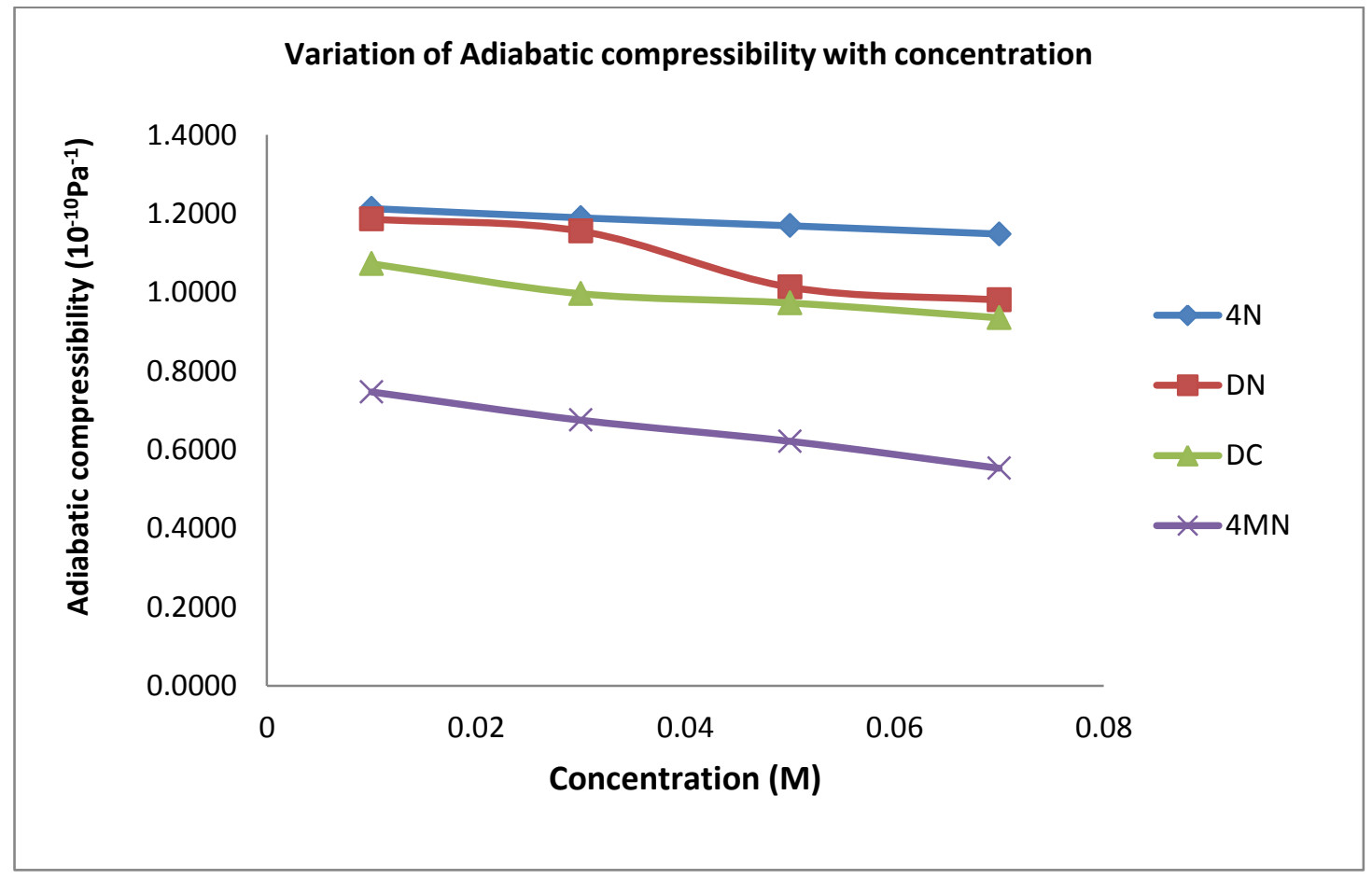

Fig. 5. Variation of Adiabatic compressibility $\left(\beta_{\mathrm{ad}}\right)$ with respect to concentration (M). 
The predominance of a particular interaction in a particular solution can also be decided by adiabatic compressibility, which is shown in Fig. 5 for all the Schiff bases in ethanol. It is observed that in ethanol solution, adiabatic compressibility decreases with increase in concentration for $4 \mathrm{~N}, \mathrm{DN}, \mathrm{DC}$ and $4 \mathrm{MN}$ compounds. It indicates the aggregation of solvent molecules around solute molecules ${ }^{20}$. This indicates the existence of strong interaction between solute and solvent. The change in adiabatic compressibility in liquid mixtures indicates that there is a definite contraction on mixing and the variation is may be due to complex formation.

The magnitude of either the solute-solute interaction or the solute-solvent interaction or both of the system has been denoted from Intermolecular Free length. Free length decreases with increase in concentration (Fig. 6) are due to compression of liquid, which indicates that the molecules are coming closer to each other and hence the intermolecular cohesion is stronger which leads the strong molecular association ${ }^{20}$.

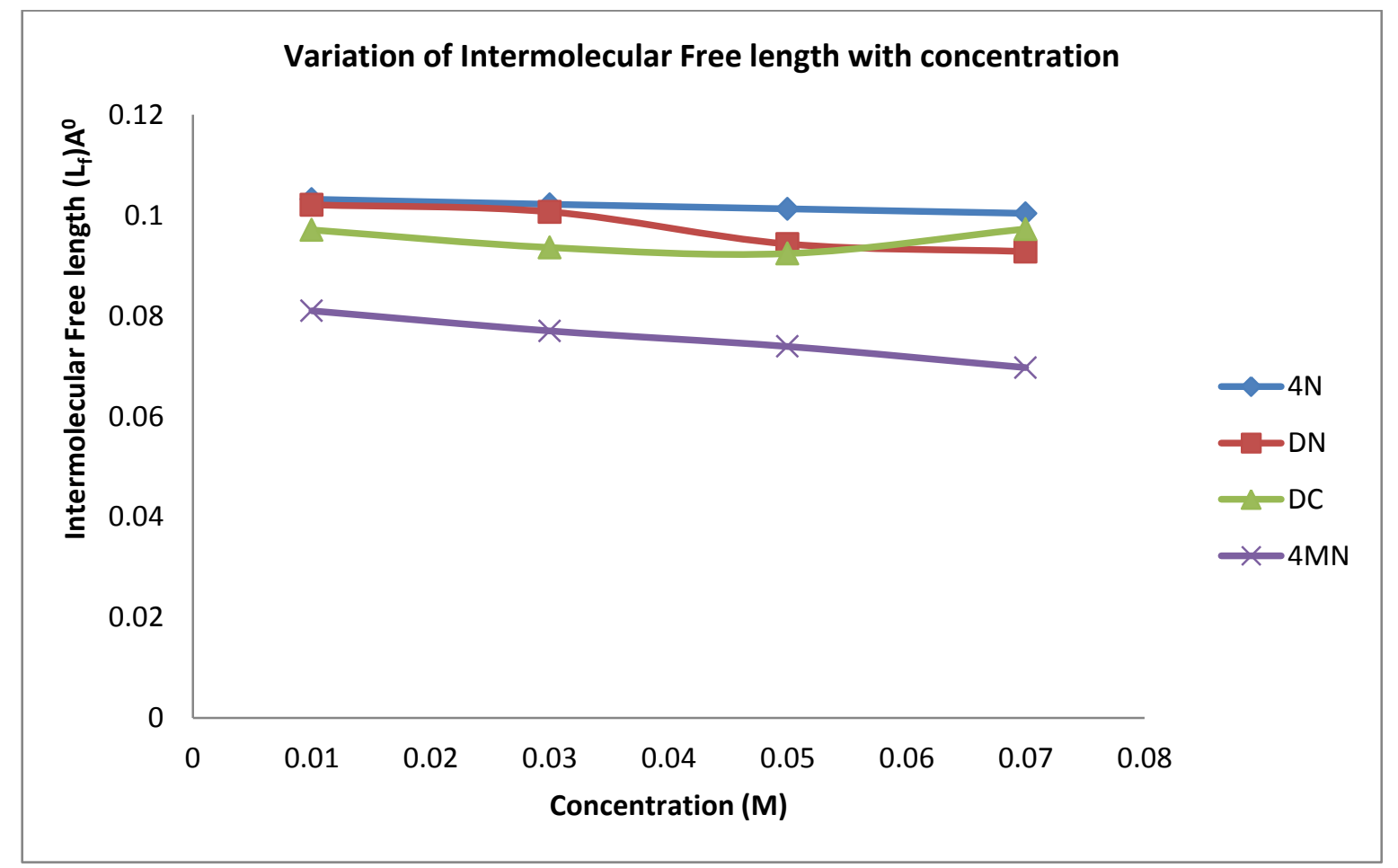

Fig. 6. Variation of Intermolecular Free length $\left(L_{f}\right)$ with respect to concentration $(M)$.

The increasing trend (Fig. 7) of acoustic impedance supports the possibility of molecular interaction between Schiff bases and alcohol molecules and it is directly proportional with ultrasonic velocity and inversely proportional to adiabatic compressibility and shows similar behaviour to that of ultrasonic velocity and opposite to that of adiabatic compressibility $^{21,25-27}$. The internal pressure decreases with increase in concentration (Fig. 8), which indicates the decrease in cohesive forces. The reduction in internal pressure may be due to loosening of cohesive forces leading to breaking the structure of the solute. Due to weakening of intermolecular forces of attraction the internal pressure should fall. Decrease in internal pressure indicates that there is a weak interaction between the solute and solvent molecules ${ }^{22}$. 


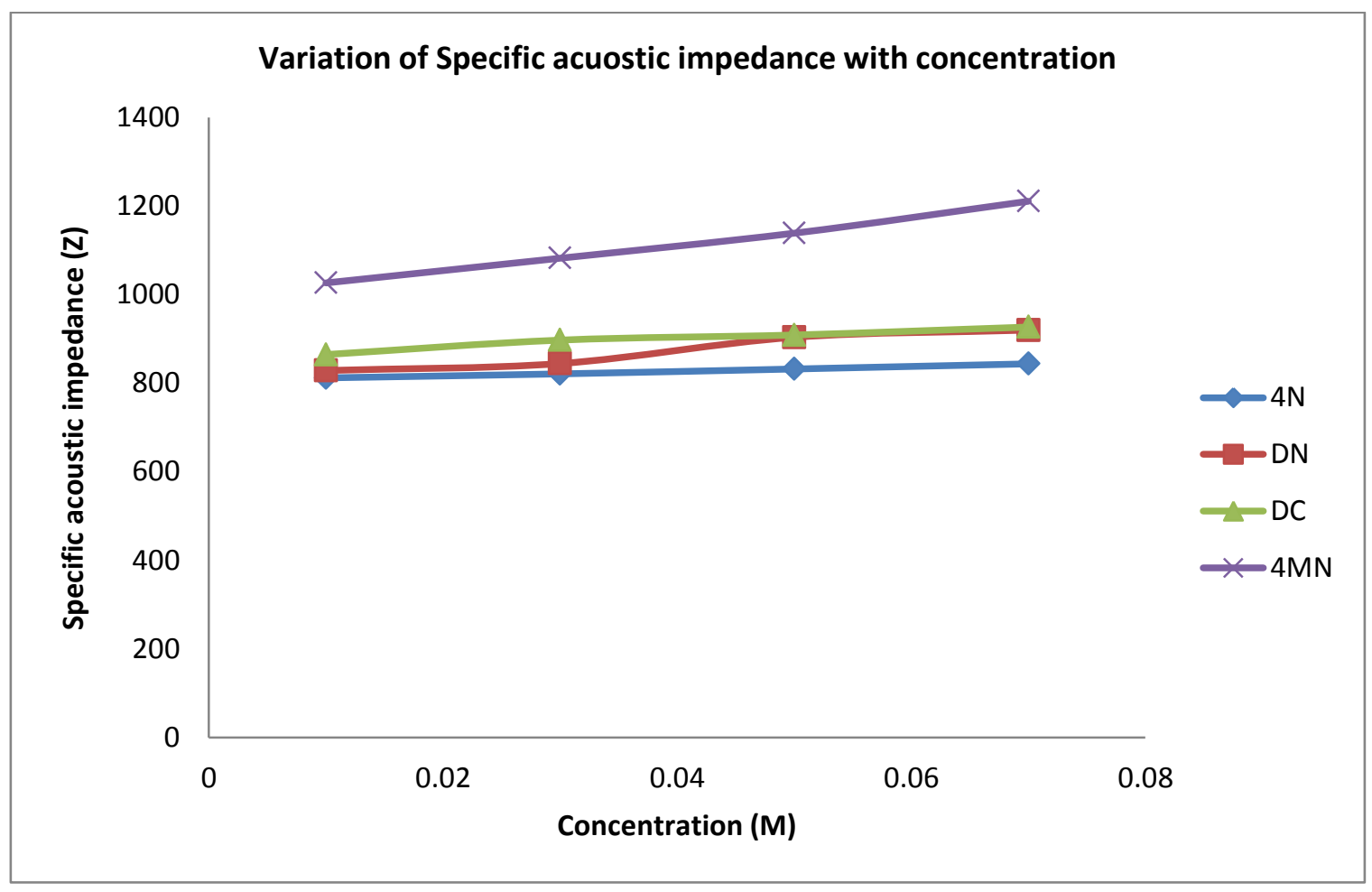

Fig. 7. Variation of Acoustic impedance (Z) with respect to concentration (M).

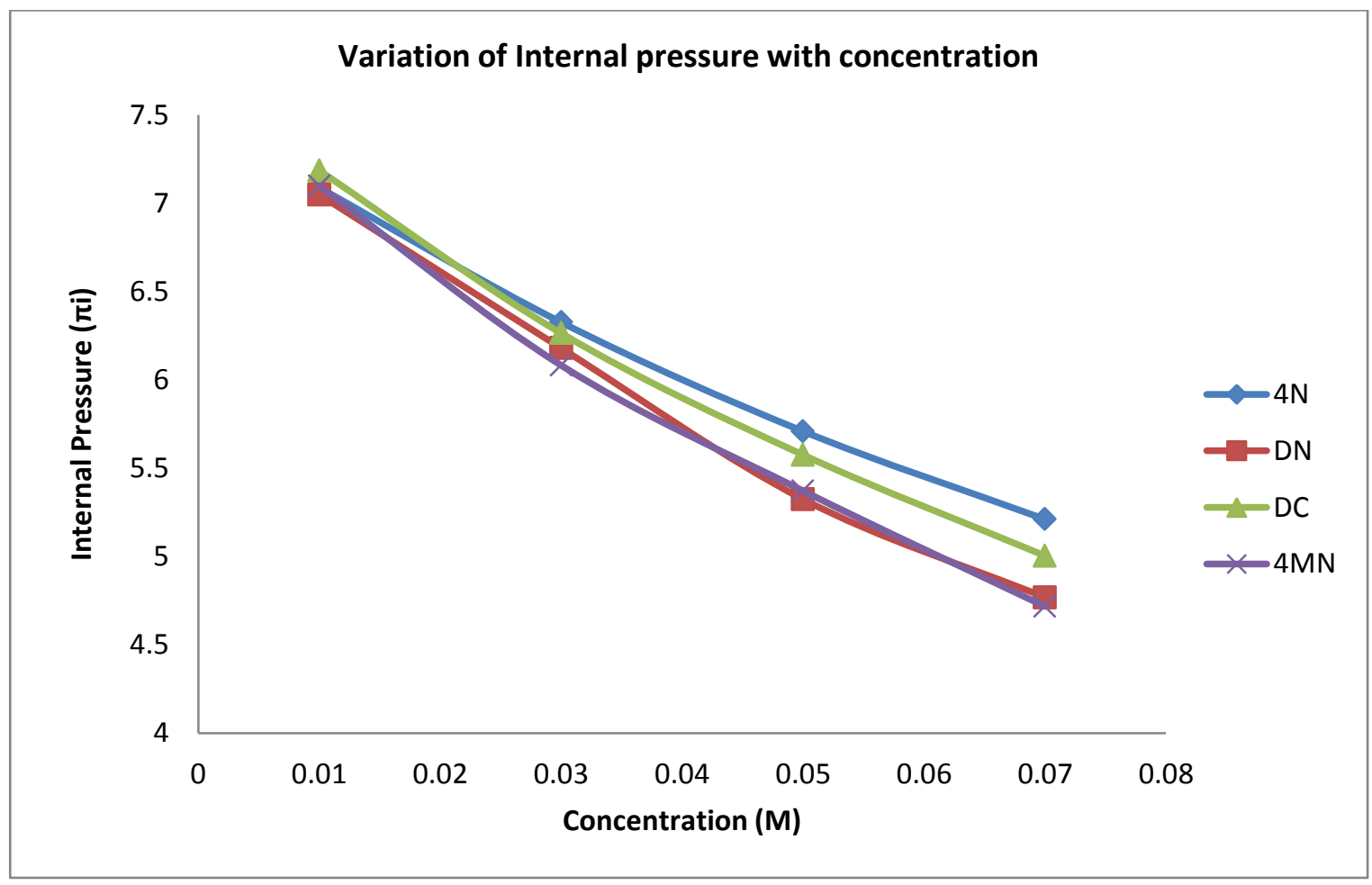

Fig. 8. Variation of Internal pressure $\left(\pi_{\mathrm{i}}\right)$ with respect to concentration (M). 
Free volume is the average volume in which the center of molecule can move due to repulsion of the surrounding molecules. The free volume increases with increase in concentration (Fig. 9). The decrease in molecular association causes an increase in free volume. The increase in free volume may be attributed to lose packing of the molecules inside the shield, which may be brought about by weakening of molecular interactions ${ }^{23}$. Thus free volume is an inverse function of internal pressure. Hence, increase in free volume causes internal pressure to decrease, which indicates the existence of solute-solvent interactions.

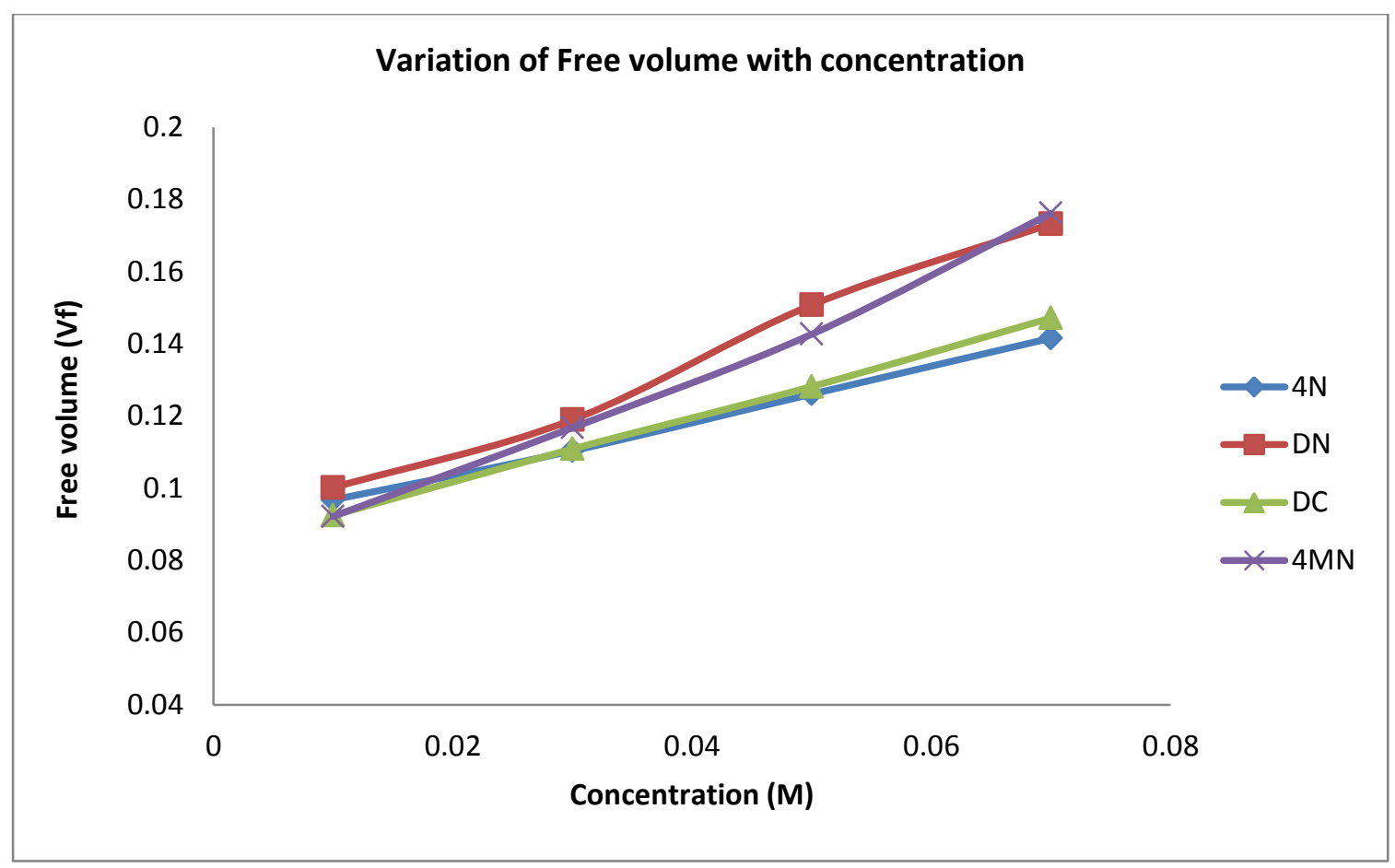

Fig. 9. Variation of Free volume $\left(\mathrm{V}_{\mathrm{f}}\right)$ with respect to concentration $(\mathrm{M})$.

\section{2. Anti-microbial activities}

Schiff base compounds possess a wide range of biological activities, these multiprolonged activities are associated with different substituents and the unsaturation of $\mathrm{C}=\mathrm{N}$ moiety in between the aryl rings. Hence, it is intended to examine their antimicrobial activities against their respective microbes-bacterial strains.

\section{2. 1. Antibacterial sensitivity assay}

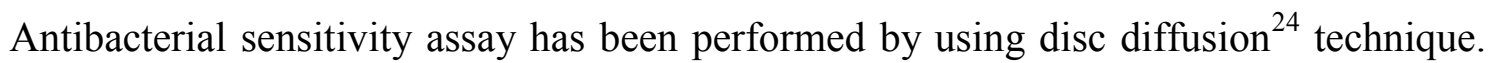
In each Petri plate about $0.5 \mathrm{ml}$ of the test bacterial sample has been spread uniformly over the solidified Mueller Hinton agar using sterile glass spreader. Then the discs with $5 \mathrm{~mm}$ diameter made up of Whatmann No.1 filter paper, impregnated with the solution of the compound have been placed on the medium using sterile forceps. The plates have been incubated for 24 hours at $37^{\circ} \mathrm{C}$ by keeping the plates upside down to prevent the collection of water droplets over the medium. After 24 hours, the plates have been visually examined and the diameter values of the zone of inhibition were measured. Triplicate results have been recorded by repeating the same procedure. 
The antibacterial activities of all the synthesized Schiff base compounds have been studied against three gram positive pathogenic strains Micrococcus luteus, Bacillus substilis, Staphylococcus aureus and two gram negative strains Escherichia coli and Pseudomonas species. The disc diffusion technique ${ }^{24}$ was followed at a concentration of $250 \mu \mathrm{g} / \mathrm{mL}$ with Ciproflaxin taken as the standard drug. The zone of inhibition is compared using Table 1 and the corresponding clustered column chart is shown in Fig. 3.

Table 3. Antibacterial activities of Schiff bases (entries 1-4).

\begin{tabular}{|c|c|c|c|c|c|c|}
\hline \multirow{2}{*}{ Entry } & \multirow{2}{*}{ Compound } & \multicolumn{5}{|c|}{ Zone of Inhibition (mm) } \\
\cline { 3 - 7 } & & \multicolumn{3}{|c|}{ Gram positive bacteria } & \multicolumn{2}{c|}{ Gram negative bacteria } \\
\cline { 3 - 7 } & & B. subtilis & Micrococcus & S. aureus & E.coli & Pseudomonas \\
\hline 1 & $4 \mathrm{~N}$ & 16 & 8 & 16 & 23 & 12 \\
\hline 2 & DN & 8 & -- & 10 & 7 & -- \\
\hline 3 & DC & 15 & 10 & 21 & 8 & 9 \\
\hline 4 & $4 \mathrm{MN}$ & 20 & 16 & 24 & 18 & 17 \\
\hline Standard & Ciproflaxin & 36 & 34 & 34 & 32 & 30 \\
\hline Control & DMSO & -- & -- & -- & -- & -- \\
\hline
\end{tabular}

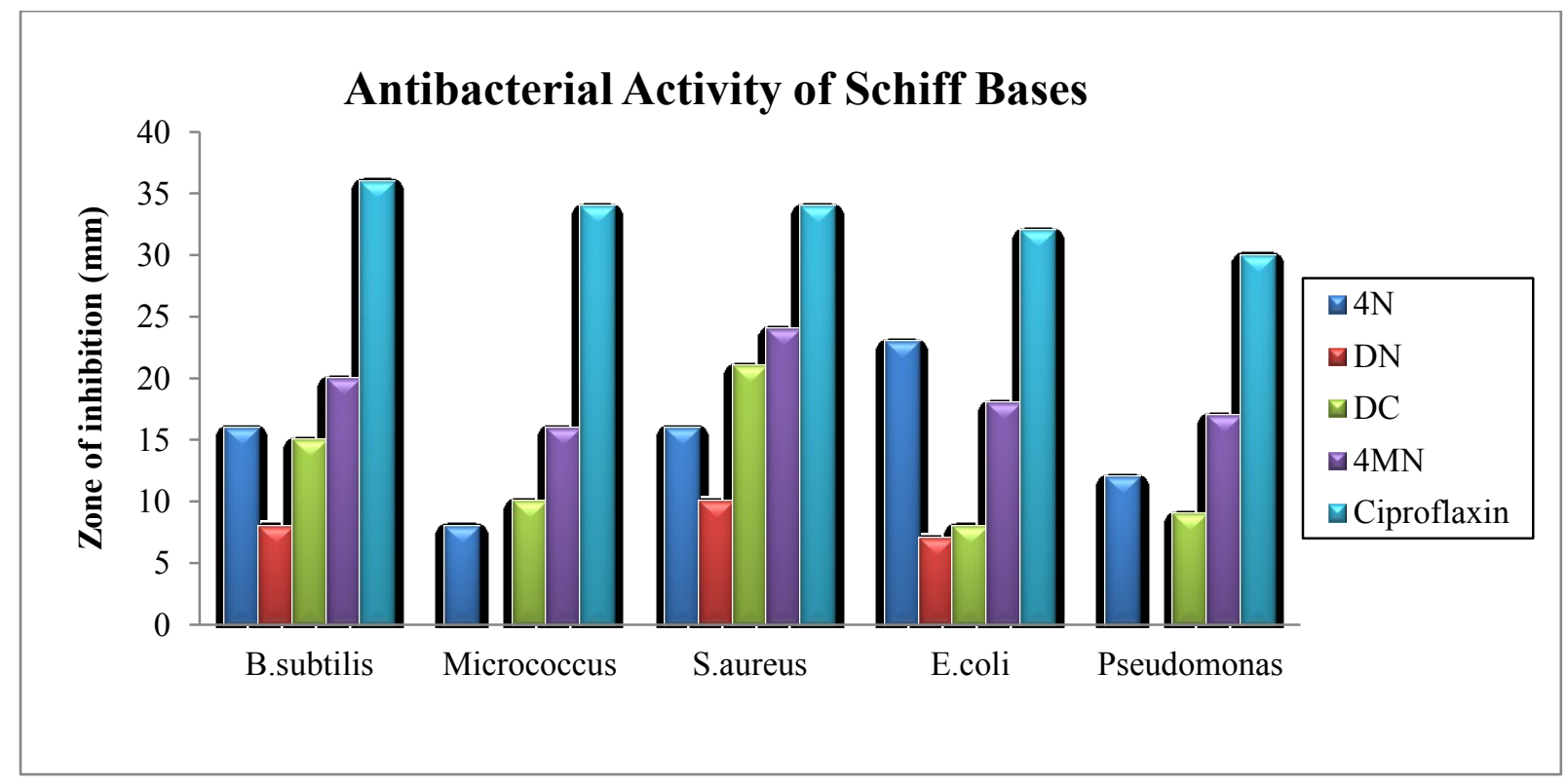

Fig. 3. Antibacterial activity. 
From the table, it is evident that all the synthesized Schiff base compounds were biologically active against $B$. subtilis, $S$. aureus and E. coli species. Especially, the compound $4 \mathrm{MN}$ has shown good activity against $S$. aureus than other three compounds. The compound $4 \mathrm{~N}$ has also shown good activity against $E$. coli than other compounds under investigation. However the compound DN has shown poor activity against Micrococcus and Pseudomonas.

\section{CONCLUSION}

Totally four number of Schiff base compounds have been synthesized by ultrasonic irradiation technique and are characterized by UV, IR and NMR spectra. The Ultrasonic velocity, density, viscosity are measured and related acoustical parameters were calculated from the measured data. The existence of molecular interactions in solute-solvent is favoured in the system, confirmed from the $U, \rho, \eta, \beta_{(\mathrm{ad})}, \mathrm{L}_{\mathrm{f}}, \mathrm{V}_{\mathrm{f}}, \mathrm{Z}$ and $\pi_{\mathrm{i}}$. Hence it is concluded that there is existence of molecular interactions between Schiff base compounds and alcohol. Internal pressure gives the idea of the solubility characteristics. The antibacterial activity of the four Schiff bases have been studied using Bauer-Kirby method and shown considerable activity.

\section{References}

[1] Karthikeyan S.M, Prasad J.D, Poojary B, Bhat S.K, Bioorg. Med. Chem. 14 (2006) 7482.

[2] Singh K, Barwa M.S, Tyagi P, Eur. J. Med. Chem. 41 (2006) 147.

[3] Rakesh K.P, Shiva Prasad K, Shridhara Prasad K, Int. J. Res. Chem. Environ. 2 (2012) 221.

[4] Sridhar S.K, Saravan M, Ramesh A, Eur. J. Med. Chem. 36 (2001) 615.

[5] Walsh O.M, Meegan M.J, Prendergast R.M, Nakib T.A, Eur. J. Med. Chem. 31 (1996) 989.

[6] Dabholkar V.V, Ansari F.Y, Ind. J. Chem. 47B (2008) 1759.

[7] Antosiewicz, Juszkiewicz A, D.J. Shugar, J. Phys. Chem. 86 (1982) 4831.

[8] Chennarayappa, C.K., Rambabu P.V, Raman, G.K, Acoust. Lett., 15 (1991) 83.

[9] Ali A., A.K. Nain, V.K. Sharma, S. Ahmad, Ind. J. Phys. 75B (2001) 519.

[10] Ali, A., A.K. Nain, D. Chand, R. Ahmad, Bull. Chem. Soc. Japan 79 (2006) 702

[11] Baluja S, Parsania P.H, Asian J. Chem. 7 (1995) 417.

[12] Baluja S, P.H. Parsania., Asian J. Chem. 9 (1997) 149.

[13] Baluja S, S. Oza, Fluid Phase Equilibria 208 (2003) 83.

[14] Baluja S., P. Inamdar, M. Soni, Wuli Huaxue Xuebao 20 (2004) 1104.

[15] Baluja S., A. Solanki, N. Kachhadia, Russ. J. Phy. Chem. 81 (2007) 742.

[16] Baluja S., N. Kachhadia, M. Soni, Int. J. Appl. Chem. 4 (2008) 71-80. 
[17] Nagar A.A, Patel P.R, Dhobi A, Bendale A. R, Chugh N.N, Asian J. Curr. Chem. 1(2) (2011).

[18] Kharkale S.S, Wagh M.S, Agrawal P.S, Paliwal L.J, Proceedings of Eighteenth National Symposium on Ultrasonics, Vellore 2009, 502-504.

[19] Sunanda et al., Int. J. Pharm. Pharmaceu. Science 5(1) (2013) 76-79.

[20] Patil K.C, Umare V.D., Int. J. Res. Pure \& Appl. Phys. 2(4) (2012) 25-27.

[21] Padma S. There., Rasayan J. Chem. 6(2) (2013) 111-116.

[22] Lin W, Tsay S.J, J. Phys. Chem. 74 (1990) 1073.

[23] Tadkalkar Alka, Pawar Pravina, Bichile G.K, J. Chem \& Phar. Res. 3(3) (2011) $165-168$.

[24] Bauer A.W, Kirby W.M.M, Sherris J.C, Truck M, Am. J. Clin Patho. 45 (1966) 493.

[25] Arun Mishra, Jaynt Rathod, Dipti Namera, Shailesh Thakrar, Anamik Shah, International Letters of Chemistry, Physics and Astronomy 11(3) (2014) 193-201.

[26] Pankaj Chovatiya, Charmy Mehta, Hardik Senjani, Anamik Shah, Hitendra S. Joshi, International Letters of Chemistry, Physics and Astronomy 12 (2014) 26-30.

[27] Ankita Bhalu, Kalpesh Vilapara, Minaxi Maru, Manish Shah, International Letters of Chemistry, Physics and Astronomy 12 (2014) 51-55. 